\title{
Genomic structure and transcriptional regulation of the human NAD+-dependent 15-hydroxyprostaglandin dehydrogenase gene
}

\author{
A Nandy, S Jenatschke, B Hartung, K Milde-Langosch ${ }^{1}$, A-M Bamberger ${ }^{1}$ and \\ B Gellersen \\ IHF Institute for Hormone and Fertility Research, University of Hamburg, Falkenried 88, 20251 Hamburg, Germany \\ ${ }^{1}$ Institute of Pathology, Department of Gynaecopathology, University Hospital of Hamburg, Martinistrasse 52, 20246 Hamburg, Germany \\ (Requests for offprints should be addressed to B Gellersen who is now at Endokrinologikum Hamburg, Falkenried 88,20251 Hamburg, Germany; \\ Email: gellersen@endokrinologikum.com)
}

\begin{abstract}
The $\mathrm{NAD}^{+}$-dependent 15-hydroxyprostaglandin dehydrogenase (PGDH) is a catabolic enzyme that controls the biological activities of prostaglandins by converting them into inactive keto-metabolites. Here we report the genomic organisation of the complete human PGDH gene and characterise its transcriptional regulation. The PGDH gene spans about $31 \mathrm{~kb}$ on chromosome 4 and contains 7 exons. Within $2.4 \mathrm{~kb}$ of the $5^{\prime}$-flanking sequence we identified two regions with clustered putative transcription factor binding sites. The distal promoter element PGDH-DE (positions-2152/-1944 relative to the start codon) contains binding sites for Ets and activating protein-1 (AP-1) flanked by two cAMP-responsive element-binding protein binding sites (CREB1, CREB2), whereas the proximal element PGDH-PE $(-235 /-153)$ includes an Ets and an AP-1 binding sequence. By electrophoretic mobility shift assay, no high affinity binding of Ets or AP-1 factors was observed with PGDH-PE, whereas we confirmed interaction of members of the Ets, AP-1 and CREB families of transcription factors with PGDH-DE. Transcriptional control of the PGDH promoter was assessed by transiently transfecting JEG-3 choriocarcinoma cells. A luciferase reporter gene construct containing the PGDH-PE was not induced by $\mathrm{c}$-jun/c-fos in the absence or presence of co-expressed Ets-1. A construct carrying the PGDH-DE in front of the minimal homologous promoter was activated by co-transfection of expression vectors for AP-1 proteins. Mutation of the AP-1 or CREB2 site reduced the response to c-jun/c-fos, whereas mutation of the Ets site of the distal element reduced basal promoter activity. CREB activated the PGDH-DE construct through the CREB1 site. These results defined the distal element as an integrator of transcriptional regulation by AP-1, Ets and CREB proteins.
\end{abstract}

Journal of Molecular Endocrinology (2003) 31, 105-121

\section{Introduction}

$\mathrm{NAD}^{+}$-dependent 15-hydroxyprostaglandin dehydrogenase (type-I 15-PGDH; EG 1.1.1.141) plays an important role in the control of the biological activities of prostaglandins (PG). PGDH catalyses the first step of $\mathrm{PG}$ catabolism, the oxidation of the 15-hydroxyl group, which results in a reversible inactivation of PGs into their 15 keto-metabolites (Ensor \& Tai 1995, Okita \& Okita 1996). An absolute requirement for PG metabolism by PGDH in perinatal development has been revealed by the recent generation of PGDH-deficient mice.
Pgdh ${ }^{-}$- pups die shortly after birth because of defective remodelling of the ductus arteriosus (Coggins et al. 2002). In the human utero-placental unit, PGs are produced by the amnion, chorion and decidua, and the activity of PG synthetases increases at the time of labour (Okazaki et al. 1981). It has been suggested that the high level of PGDH expression in the chorion protects the myometrium from biologically active PGs during pregnancy to maintain a quiescent uterus (Mitchell et al. 1993, Patel \& Challis 2001). PG inactivation is greatly reduced only at the time of parturition, because of diminished PGDH activity (Van Meir et al. 1997b, 
Pomini et al. 2000). Patients in preterm labour have markedly reduced levels of PGDH activity and PGDH mRNA in chorionic trophoblasts (Sangha et al. 1994, Van Meir et al. 1997a), and PGDH activity is reduced in the myometrium of women in labour, both at term and preterm (Giannoulias et al. 2002). Down-regulation of PGDH expression thus appears to play a main role in the initiation of labour at term or preterm. As preterm birth is the predominant cause of neonatal mortality, the prevention of preterm labour is a major goal in obstetrics (López Bernal \& Watson 1992). A better understanding of the regulation of PGDH expression may contribute to improved clinical management of this condition.

PGDH cDNA has been cloned from human placenta, mouse lung, guinea pig uterus and rat intestine (Ensor et al. 1990, Matsuo et al. 1996, Bracken et al. 1997, Zhang et al. 1997). At present the genomic organisation of the PGDH gene is only known in mice (Matsuo et al. 1997). The human gene is located on chromosome 4 (Pichaud et al. 1997). Based on the high homology between human and mouse PGDH cDNAs, we devised a long extension PCR strategy to amplify the introns predicted from the structure of the mouse gene and report here the genomic structure of human PGDH.

We have recently isolated $3.5 \mathrm{~kb}$ of the 5 '-flanking region of the human PGDH gene and reported the presence of several potential binding sites for transcription factors including activating protein-1 (AP-1), Ets and cAMP-responsive element-binding protein (CREB) within $2 \cdot 4 \mathrm{~kb}$ of the 5'-flanking region (Greenland et al. 2000). AP-1 belongs to the family of basic region/leucine zipper transcription factors and consists of homo- or heterodimers of Jun, Fos or activating transcription factor (ATF) proteins (Karin et al. 1997). Jun-Fos dimers bind to 12-O-tetradecanoyl-phorbol-13acetate (TPA)-responsive elements, while Jun-ATF dimers preferentially bind to the cAMP-responsive element (GRE) (Karin et al. 1997). Unlike AP-1, members of the Ets family of transcription factors bind to their target sequence as monomers, but share with AP-1 an involvement in a wide range of biological processes including cellular proliferation, differentiation, transformation and apoptosis $(\mathrm{Li}$ et al. 2000). In fact, Ets proteins exert many of their activities by protein-protein interactions with other nuclear factors including AP-1 (Li et al. 2000, Chinenov \& Kerppola 2001).
We have previously demonstrated an involvement of Ets and AP-1 in the transcriptional regulation of $\mathrm{PGDH}$ promoter constructs extending to $2 \cdot 4 \mathrm{~kb}$ upstream of the transcriptional start site. Here we analyse more closely two clusters of response elements in the distal and proximal regions of the promoter.

\section{Materials and methods}

\section{Isolation and cloning of intronic PGDH DNA}

To amplify the intronic regions of the human PGDH gene, ten sense and antisense oligonucleotide primers to the human PGDH cDNA, flanking the splicing sites predicted from the mouse PGDH cDNA, were synthesised (Table 1). Intervening sequences were amplified by PCR using $250 \mathrm{ng}$ genomic DNA (Roche Applied Science, Karlsruhe, Germany), $400 \mathrm{nM}$ sense and antisense primers, $2.5 \mathrm{U}$ Expand $20 \mathrm{~kb}^{\text {PLUS }}$ polymerase (Roche Applied Science) and $500 \mathrm{nM}$ dNTPs in a final volume of $25 \mu \mathrm{l}$. The conditions for PGR were: $92{ }^{\circ} \mathrm{C}$ for $2 \mathrm{~min}$, then 10 cycles of $92{ }^{\circ} \mathrm{C}$ for $10 \mathrm{~s}$, $62{ }^{\circ} \mathrm{C}$ for $30 \mathrm{~s}$ and $68{ }^{\circ} \mathrm{C}$ for $18 \mathrm{~min}$, followed by 20 cycles of $92{ }^{\circ} \mathrm{C}$ for $10 \mathrm{~s}, 62{ }^{\circ} \mathrm{C}$ for $30 \mathrm{~s}$ and $68{ }^{\circ} \mathrm{C}$ for $18 \mathrm{~min}$ with $10 \mathrm{~s}$ per cycle increase, and a final extension at $68{ }^{\circ} \mathrm{C}$ for $7 \mathrm{~min}$. The PCR products were cloned into pCR-TOPO XL-1 (Invitrogen, Karlsruhe, Germany) following the manufacturer's protocol. Inserts were sequenced by the dideoxy chain termination method using an automated DNA sequencer.

\section{Southern blotting of genomic DNA}

Genomic DNA was purified from human placenta by a standard procedure using the Nucleobond Ax Kit (Macherey-Nagel, Düren, Germany). Twenty micrograms of genomic DNA were digested with the restriction enzymes SstI, XbaI, BglI or BamHI, separated by electrophoresis on a $0.9 \%$ agarose gel and blotted onto positively charged nylon membrane. Genomic fragments were mapped by hybridisation with a digoxygenin-labelled probe generated by PGR with primer pair PGDH-8/ PGDH-36 (see Table 1). The blot was hybridised overnight at $68{ }^{\circ} \mathrm{C}$ in $0.25 \mathrm{M} \mathrm{Na}_{2} \mathrm{HPO}_{4}(\mathrm{pH} 7 \cdot 2)$, $20 \%$ SDS, $1 \mathrm{mM}$ EDTA and $0.5 \%$ blocking reagent and then washed and immunodetected following the recommendations of the DIG 
Table 1 Sequence of human PGDH-specific oligonucleotide primers. Positions on the human PGDH cDNA are given relative to the ATG start codon

\begin{tabular}{|c|c|c|c|}
\hline & Sequence & $\begin{array}{l}\text { Position } \\
\text { (orientation) }\end{array}$ & Application \\
\hline $\begin{array}{l}\text { Primer name } \\
\text { PGDH-8 } \\
\text { PGDH-36 }\end{array}$ & $\begin{array}{l}\text { CCAGCAGTGGCTGCACCATG } \\
\text { TGCTCATGCAGGGCAGCTTTAC }\end{array}$ & $\begin{array}{l}-17-+3(\mathrm{~s}) \\
234-266 \text { (as) }\end{array}$ & $\begin{array}{l}\text { Southern } \\
\text { hybridization }\end{array}$ \\
\hline $\begin{array}{l}\text { PGDH-37 } \\
\text { PGDH-38 }\end{array}$ & $\begin{array}{l}\text { CAGTGCGATGTGGCTGACCAGCAACAACT } \\
\text { ACCAAAATGTCCAGTCTTCCAAAGTGGTCTACA }\end{array}$ & $\begin{array}{l}184-212(s) \\
234-266 \text { (as) }\end{array}$ & $\begin{array}{l}\text { Amplification } \\
\text { of intron } 2\end{array}$ \\
\hline $\begin{array}{l}\text { PGDH-39 } \\
\text { PGDH-40 }\end{array}$ & $\begin{array}{l}\text { TGCTGGAGTGAATAATGAGAAAAACTGGGAAAAA } \\
\text { TGTAATCCAAACCAAGATAGGTTCCACTGATAACA }\end{array}$ & $\begin{array}{l}273-306 \text { (s) } \\
330-364 \text { (as) }\end{array}$ & $\begin{array}{l}\text { Amplification } \\
\text { of intron } 3\end{array}$ \\
\hline $\begin{array}{l}\text { PGDH-41 } \\
\text { PGDH-42 }\end{array}$ & $\begin{array}{l}\text { AAGGCGGCATCATTATCAATATGTCATCTTTAGCA } \\
\text { ATCCAACTATGCCATGCTTTGAAGCACAATAAACC }\end{array}$ & $\begin{array}{l}386-420 \text { (s) } \\
447-481 \text { (as) }\end{array}$ & $\begin{array}{l}\text { Amplification } \\
\text { of intron } 4\end{array}$ \\
\hline $\begin{array}{l}\text { PGDH-43 } \\
\text { PGDH-44 }\end{array}$ & $\begin{array}{l}\text { CTTCAAAGCATGGCATAGTTGGATTCACAC } \\
\text { AATGGCATTCAGTCTCACACCACTGTTCATA }\end{array}$ & $\begin{array}{l}458-487 \text { (s) } \\
513-543 \text { (as) }\end{array}$ & $\begin{array}{l}\text { Amplification } \\
\text { of intron } 5\end{array}$ \\
\hline $\begin{array}{l}\text { PGDH-45 } \\
\text { PGDH-46 }\end{array}$ & $\begin{array}{l}\text { CAGCCATCCTTGAATCAATTGAAAAAGAAG } \\
\text { AATGAGTGTTATCAATCCATTGGCAATCAA }\end{array}$ & $\begin{array}{l}563-592 \text { (s) } \\
670-699 \text { (as) }\end{array}$ & $\begin{array}{l}\text { Amplification } \\
\text { of intron } 6\end{array}$ \\
\hline
\end{tabular}

(s), sense; (as), antisense.

Luminescent Detection Kit protocol (Roche Applied Science). The chemiluminescense substrate CDP-Star (Tropix, Bedford, MA, USA) was used for visualisation following the manufacturer's protocol. Light emission was recorded on Kodak XAR-5 film.

\section{Cell culture}

Cell lines used in this study included the human choriocarcinoma cell line JEG-3 and the Jurkat human leukaemic $\mathrm{T}$ lymphoblast cell line (European Collection of Animal Cell Cultures, Salisbury, Hants, UK). JEG-3 cells were cultured in Dulbecco's modified Eagle's medium/Ham's F-12 with $10 \%$ fetal calf serum (FCS), and Jurkat cells were maintained in Iscove's minimal essential medium with $10 \%$ FCS. All media were supplemented with $100 \mathrm{U} / \mathrm{ml}$ penicillin and $100 \mu \mathrm{g} / \mathrm{ml}$ streptomycin.

\section{Reporter gene constructs and expression vectors}

All luciferase reporter gene constructs were generated in the pGL3-Basic plasmid (Promega, Mannheim, Germany). The PGDH promoter/ luciferase reporter constructs PGDH-2368/luc3 and PGDH-388/luc3 have been described pre- viously (Greenland et al. 2000). For construction of the minimal promoter vector PGDH-80/luc3, the fragment $-80 /-8$ relative to the ATG start codon was created by annealing complementary oligonucleotides with BglII and HindIII overhangs and insertion into the respective sites of pGL3Basic. The PGDH-DE/-80/luc3 vector was constructed by generating a $-2152 /-1944$ fragment (DE, distal element) by PGR, using PGDH-2368/ luc3 as the template and primers which added a $5^{\prime}$-KpnI and a 3'-NheI site. This fragment was inserted into the KpnI and NheI sites of the minimal promoter construct PGDH-80/luc3. Individual or combined mutations of the AP- 1 and Ets binding sites were introduced into PGDH-388/ luc3 by site-directed mutagenesis (Quik Change PCR Mutagenesis System; Stratagene, Amsterdam, The Netherlands). For generation of PGDH-388 Etsmut/luc3, the nucleotide G $(-220)$ was mutated to A using complementary oligonucleotides (5'-CGGTGTGGGAGTGCaGAAGGGAAA GATCG-3'; sense sequence) with a point mutation (lower case) to destroy the Ets binding site (underlined). The PGDH-388APlmut/luc3 construct was generated by using complementary oligonucleotides (5'-CAGGGGGCAGGTGACAtg GTCGTGGGTTCG-3'; sense sequence) with $\overline{\text { two }}$ point mutations (lower case) $(-166 /-165)$ to destroy the AP-1 binding site (underlined). 
These oligonucleotides were also used to mutate the AP-1 site of PGDH-388Etsmut/luc3 for generation of the double mutant PGDH-388AP1/ Etsmut/luc3. The inserts of the PCR products were excised with Acc65I and BglII and inserted into the respective sites of pGL3-Basic. Sequence analysis verified the presence of the mutations.

Site-directed mutagenesis was also used to mutate individual elements in PGDH-DE/-80/ luc3 (see Figs 3 and 7). PGDH-DE/CREB1 mut/-80/luc3 was generated with complementary oligonucleotides (5'-TGTCTGAATCGAGTGCT GtgGTCGTTGTGCG-3'; sense sequence) to mutate the most 5' CREB binding sequence in the distal enhancer, whereas the $3^{\prime}$ CREB binding sequence was mutated with complementary oligonucleotides 5'-CTATCGTTGACTCATTGCACT TTGtgCTCAATCAATCTTC-3' (sense) to generate PGDH-DE/CREB2mut/-80/luc3. AP-1 or Ets binding sequences were mutated to generate PGDH-DE/AP1mut/-80/luc3 or PGDH-DE/ Etsmut/-80/luc3 respectively, with oligonucleotides 5'-CGAGTTGTCACTATCGTTGACTtgTT GCACTTTGACGTC-3' (sense) or 5'-CGACGG CGAAAGTGGTTCtTGTTGTTGGAG-3' (sense) respectively. For combined mutation of the AP-1 and $3^{\prime}$ CREB sites (construct PGDH-DE/AP1/ CREB2 mut/-80/luc3), complementary oligonucleotide 5'-CGAGTTGTCACTATGCTTGACTtgTT GCACTTTGtgCTCAATCAATC-3' (sense) were employed. After sequence verification, the distal enhancer regions from all mutants were excised with KpnI and NheI and inserted into the respective sites of $\mathrm{PGDH}-80 /$ luc3.

For construction of the expression vector pcDNA/ c-jun, carrying the human c-jun cDNA, human genomic DNA was amplified with Expand polymerase (Roche Applied Science) using primers 5'TGAGGCAGACAGACAGACACAGC-3' (sense) and 5'-GTTAAGGAAAGCAGGCGAGAAAGA3' (antisense). The PCR product was digested with Acc65I and NotI, and the resulting fragment spanning the sequence $-704 /+1213$ relative to the start ATG of c-jun mRNA was cloned into pcDNA3 $\cdot 1(+)$ (Invitrogen). Human c-fos cDNA was amplified by RT-PGR with Pfx polymerase (Life Technologies, Karlsruhe, Germany) from Jurkat cells which had been stimulated with the phorbol ester TPA $\left(5 \times 10^{-8} \mathrm{M}\right)$ and Ionomycin $(1 \mu \mathrm{g} / \mathrm{ml})$ (Sigma Chemical Co., St Louis, MO, USA) for $12 \mathrm{~h}$. The primers were: 5'-GAGCAACTGAGAAGCGAA
GACTGAG-3' (sense) and 5'-TAAGGAGAAAG AGAAAAGAGACACA-3' (antisense). The PGR product spanning the sequence $-140 /+1457$ relative to the start codon was digested with NotI at position -110 and ligated into the NotI and EcoRV sites of pcDNA3 $1(-)$.

The coding sequences for human FosB, FosB2, Fra-1 and Fra-2 were amplified by PCR using cDNA prepared from MDA-MB231 breast cancer cells as template with the following primers which carried 5'-overhangs with a HindIII site in the forward (f) primer and a BamHI site in the reverse (r) primer (restriction sites underlined):

FosB-f-Hind: 5'-CGGGAAGCTTACGTCAGG GTGGTCACAGGG-3',

FosB-r-Bam: 5'-GCGGGGATCGCTCTCTCG CCGATGTGTTTG-3',

Fral-f-Hind: 5'-GGGGAAGGTTTGTACGCG GCAGAGCGGCGAG-3',

Fral-r-Bam: 5'-GCGGGGATCGGGCATCTG CAGGGAGTAGGGG-3',

Fra2-f-Hind: 5'-CGGCAAGGTTATCATGTA CGAGGATTATCGC-3',

Fra2-r-Bam: 5'-GCGGGGATCGAGGGAGGT GCACTGGGTTAC-3'.

With the FosB primers, the full-length coding sequence and the smaller splice variant generating FosB2 (Yen et al. 1991) were simultaneously amplified. PCR was performed in 40 cycles with the Expand High Fidelity PCR System (Roche Applied Science) and an annealing temperature of $58{ }^{\circ} \mathrm{C}$ in the presence of $5 \%$ dimethyl sulphoxide. The amplification products of $1110 \mathrm{bp}$ (FosB), 970 bp (FosB2), 875 bp (Fra-1) and 1020 bp (Fra-2) were treated with BamHI and HindIII, and ligated into the expression vector pcDNA3 $\cdot 1(+)$ which had been cut by the same restriction enzymes. Wild-type sequences of the cDNA inserts were confirmed by sequencing on both strands. Expression plasmids pcDNA/JunB (coding for human JunB) and pCMV-2/JunD (coding for mouse JunD) (Harrison et al. 1995) were provided by Dr M Robinson (Bristol Dental Hospital, Bristol, UK) and Dr P R Dobner (University of Massachusetts Medical School, Worcester, MA, USA) respectively. An expression vector for human Ets-1 (pSG5-hEts1) was provided by Dr B Wasylyk (INSERM, Illkirch, France), and the CREB expression vector $\mathrm{pRc} / \mathrm{RSV}$-FLAG-CREB by $\mathrm{Dr}$ $\mathrm{R}$ Goodman (Vollum Institute, Portland, OR, USA). 


\section{Transient transfections}

Transfections of JEG-3 cells were performed by the calcium phosphate precipitation method using the ProFection Mammalian Transfection System (Promega). On the day before transfection, cells were plated onto 24-well culture plates at a density of $0.75 \times 10^{5}$ cells/well. Medium was changed $3 \mathrm{~h}$ before transfection. Cells were transfected with $0.75 \mu \mathrm{g}$ reporter construct and $0.2 \mu \mathrm{g}$ of each expression vector. For normalisation, $0.05 \mu \mathrm{g}$ $\beta$-galactosidase expression vector $\mathrm{pCMV} / \mathrm{LacZ}$ (kindly provided by Dr G E DiMattia, London Regional Cancer Centre, London, Ontario, Canada) were included. The total amount of DNA was kept constant by addition of promoterless pOGH (human growth hormone reporter) plasmid. Medium was replaced after $20 \mathrm{~h}$. Cells were harvested $24 \mathrm{~h}$ later in passive lysis buffer for measurement of luciferase (Promega) and $\beta$-galactosidase activities (GalactoLight; Tropix) in a Berthold luminometer (Isernhagen, Germany). All transfections were carried out in triplicate and repeated several times.

\section{Nuclear extracts and electrophoretic mobility shift assay (EMSA)}

Double-stranded oligonucleotides used as probes or competitors for EMSA were: AP-1 consensus binding site (5'-CGCTTGATGACTCAGCGG GAA-3') (sense sequence, core motif underlined), Ets consensus binding site (5'-GATCTCGAGC AGGAAGTTCGA-3') and CRE consensus (5'AGAGATTGCGTGACGTCAGAGAGCTAG-3'). Sequences of PGDH promoter elements (DE/ GREB1, DE/Ets, DE/AP1, DE/CREB2, PE/Ets, $\mathrm{PE} / \mathrm{AP1}$ and mutations thereof (denoted by the suffix ' $m$ ') are shown in Fig. 7. Double-stranded oligonucleotides were end-labelled with $\left[\gamma_{-}{ }^{32} \mathrm{P}\right] \mathrm{ATP}$ and T4 polynucleotide kinase (New England Biolabs, Schwalbach, Germany) and purified on MicroSpin G-25 columns (Amersham Pharmacia Biotech, Freiburg, Germany).

Nuclear extracts were prepared by a modification of the method of Schreiber et al. (1989) from Jurkat cells which had been stimulated for $12 \mathrm{~h}$ with $5 \times 10^{-8} \mathrm{M}$ TPA and $1 \mu \mathrm{g} / \mathrm{ml}$ Ionomycin.

EMSAs were performed by incubating $12.5 \mu \mathrm{g}$ nuclear protein (unless indicated otherwise) in bandshift buffer $(10 \mathrm{mM}$ Tris, $\mathrm{pH} 7 \cdot 5,50 \mathrm{mM}$ $\mathrm{NaCl}, 1 \mathrm{mM}$ dithiothreitol, $1 \mathrm{mM}$ EDTA, 5\% glycerol) containing $4 \times$ complete protease inhibitor (Roche Applied Science) in the presence of $1 \mu \mathrm{g}$ poly $(\mathrm{dI}-\mathrm{dC})$ for $15 \mathrm{~min}$ at $4{ }^{\circ} \mathrm{C}$. Different amounts of unlabelled competitor binding sites or $1 \mu \mathrm{l}$ antibody for supershift were added for $30 \mathrm{~min}$, followed by a 30-min incubation with 15000 c.p.m. of ${ }^{32}$ P-labelled probes, all on ice. The protein/DNA mixture was then resolved on a $4 \%$ polyacrylamide gel in Tris-borate-EDTA buffer for $1.5 \mathrm{~h}$ at $220 \mathrm{~V}$. Dried gels were exposed to $\mathrm{X}$-ray film with an intensifying screen overnight at $-80^{\circ} \mathrm{C}$. The following antibodies were employed: against Ets-1/Ets-2 (C-275; Santa Cruz Biotechnology, Santa Cruz, CA, USA), c-fos (4; Santa Cruz), FosB (102; Santa Cruz), Fra-1 (R-20; Santa Cruz), Fra-2 (Q-20; Santa Cruz), JunB (210; Santa Cruz), JunD (329; Santa Cruz), p-c-jun (KM-1, phosphospecific; Santa Cruz) and c-jun (Ab-1; Oncogene Research Products, San Diego, CA, USA). According to the supplier this latter antibody does not produce a supershift but rather blocks a gelshift if added to the protein prior to the AP-1 probe.

\section{Results}

\section{Cloning of the introns of the human PGDH gene, and determination of the genomic structure}

Comparison of the human and mouse PGDH cDNA sequences revealed a high degree of identity between these species (87\%) (Ensor et al. 1990, Matsuo et al. 1996). According to the mouse splicing sites (Matsuo et al. 1997) we designed PGR primers specific to the human PGDH cDNA flanking the putative splice sites. In a long extension PCR with human genomic DNA as the template, intervening sequences containing putative introns were amplified. Amplification products (introns 2-6) were cloned, partially sequenced from both ends and subjected to restriction analysis. These clones complement a $4.6 \mathrm{~kb}$ fragment previously cloned by us that contains $3.5 \mathrm{~kb}$ of the $5^{\prime}$-flanking region of the human PGDH gene, exons 1 and 2 and intron 1 (Greenland et al. 2000).

Based on the restriction pattern of the intronic clones we constructed a restriction map of the human PGDH gene and compared it with the recently completed $\mathrm{PGDH}$ gene sequence available at GenBank (accession no. AC096751) (Fig. 1). 


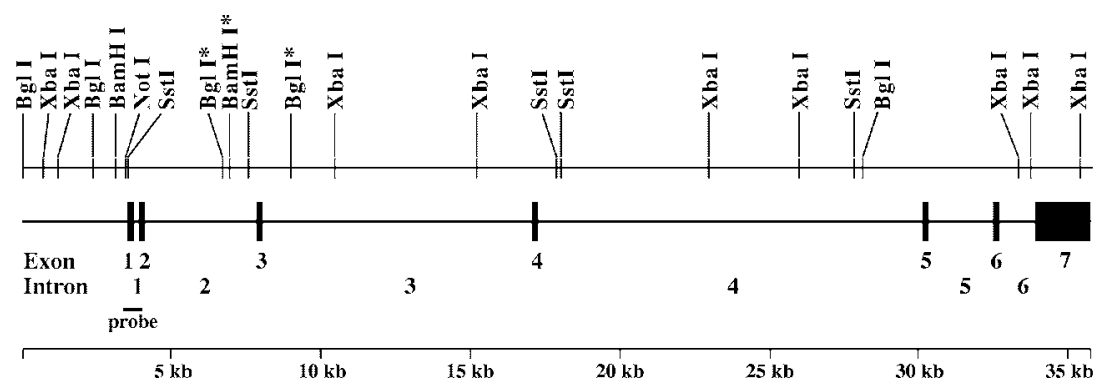

Figure 1 Restriction map of the human PGDH gene. The PGDH gene is allocated to human chromosome 4 and is approximately $31 \mathrm{~kb}$ long. The indicated restriction sites were obtained from GenBank sequences (accession no. AC09751) and confirmed by restriction analysis of intronic clones with the exception of the Bgll and BamHI sites marked by asterisks which were identified by restriction analysis and/or genomic Southern hybridisation. The location of the probe used for Southern hybridisation is shown.

Exons 1-7 span $31 \mathrm{~kb}$ on chromosome 4 which has recently been sequenced by the human genome project (Genome Sequencing Center, Washington University, School of Medicine, St Louis, MO, USA). Clone RP11-440I14 contains the PGDH gene, which carries the marker stSG4911. In order to analyse the human PGDH in a genomic Southern blot, placental DNA was digested with several restriction enzymes and probed with a PGDH fragment containing exon 1 sequence from position -17 relative to the start codon, intron 1 and 62 bases of exon 2 (see Fig. 1). The hybridisation pattern of the SstI and XbaI fragments of the genomic DNA agreed with the sequences of clone RP11-440I14 whereas the BamHI and BglI fragments did not (Fig. 2). Since the region of the probe does not contain a BglI restriction site, the two BglI bands on the Southern blot point to the fact that the digest of the placental DNA was incomplete. However, this allowed us to locate two additional BgII sites in introns 2 and 3, indicated by asterisks in Fig. 1, which are not present in the GenBank sequence. An additional BamHI site in intron 2 was located by genomic Southern hybridisation (indicated in Fig. 1 by an asterisk) which was not present in the cloned intron 2 , indicating a polymorphism. The hybridisation pattern suggests that only one copy of the PGDH gene exists in the human genome (Fig. 2).

All exon-intron junctions follow the GT-AG rule and show high homology to the mouse PGDH sequence (Matsuo et al. 1997) (Table 2). However, the sizes of the human PGDH introns are much larger.

\section{Transcriptional regulation of the human PGDH gene}

Within $2.4 \mathrm{~kb}$ of the human PGDH promoter several potential binding sites for transcription factors including AP-1, Ets, CREB and CCAAT/ enhancer-binding protein are found in two clusters (Greenland et al. 2000). The distal element PGDH-DE $(-2152 /-1944)$ contains an AP-1 site adjacent to an Ets site and flanked by two CREs (denoted CREB1 and CREB2). The proximal element PGDH-PE $(-235 /-153)$ carries an Ets and an AP-1 binding site (Fig. 3).

\section{SstI XbaI BglI BamHI}

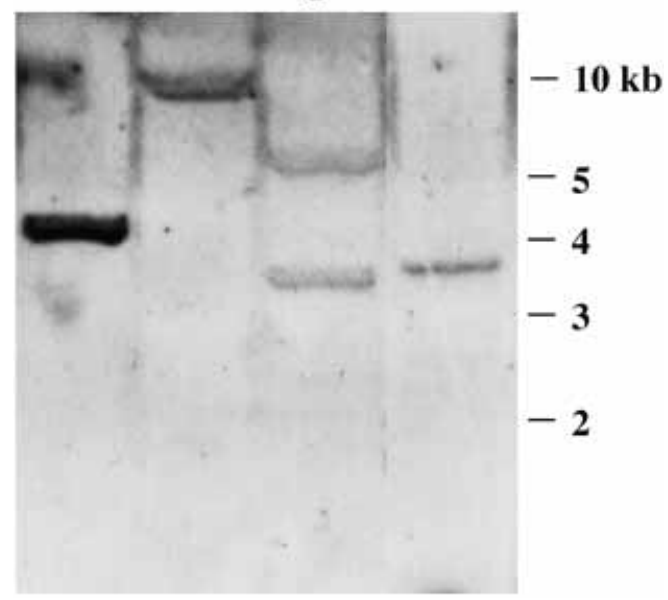

Figure 2 Southern analysis of the human genome for PGDH sequences. Genomic DNA from human placenta was digested with the indicated restriction endonucleases and subjected to Southern hybridisation with the probe indicated in Fig. 1. 
Table 2 Exon-intron junctions of the human PGDH gene. Splice positions are given relative to the ATG start codon in the human PGDH cDNA. Exon sequences are shown in capital letters; intron sequences in lower-case letters. Deviations in the corresponding mouse sequence are indicated in italics

\begin{tabular}{|c|c|c|c|c|c|c|c|}
\hline & $\begin{array}{l}\text { Size } \\
(k b)\end{array}$ & $\begin{array}{l}\text { Splice } \\
\text { position }\end{array}$ & Exon & $\begin{array}{l}\text { Intron } \\
\text { donor }\end{array}$ & $\begin{array}{l}\text { Intron } \\
\text { acceptor }\end{array}$ & Exon & Species \\
\hline \multirow[t]{2}{*}{$\begin{array}{l}\text { Intron no. } \\
1\end{array}$} & 0.29 & $93 / 94$ & $\ldots$ CCAAG & $\underset{|| \mid}{g t a a g c c g g}$. & ttgtctatag & GTAGC. . & Human \\
\hline & 0.2 & & & ga tt & $t g$ & & Mouse \\
\hline \multirow[t]{2}{*}{2} & 4.07 & $217 / 218$ & ...GAGAG & gtaagacagg. & $\begin{array}{l}\text { ttataattag } \\
\mid \text { | } \mid \text { | }\end{array}$ & $\underset{1}{\text { ACACT. . . }}$ & Human \\
\hline & 3.5 & & & $g t t$ & $c t \operatorname{tg}$ & $T$ & Mouse \\
\hline \multirow[t]{2}{*}{3} & $9 \cdot 18$ & $324 / 325$ & . . АТTTT & $\underset{|| \mid}{\operatorname{gtgagttat}}$ & ${ }_{\mid}^{\text {tctggattag }}$ & GTTTC. . & Human \\
\hline & $3 \cdot 0$ & & & $a c c \quad a$ & C & & Mouse \\
\hline \multirow[t]{2}{*}{4} & 13.07 & $421 / 422$ & . . AGCAG & gtaagggcaa. & $\begin{array}{l}\text { tctgtttcag } \\
|||| \mid\end{array}$ & $\begin{array}{c}\text { GACTC. . } \\
\text { । }\end{array}$ & Human \\
\hline & 1.9 & & & $t t$ & $C g a c$ & G & Mouse \\
\hline \multirow[t]{2}{*}{5} & $2 \cdot 2$ & $498 / 499$ & $\ldots$ CAGCG & $\underset{|| \mid}{\operatorname{gtgaggetac}}$ & taattggcag & $\begin{array}{l}\text { TTGGC. . . } \\
\text { । }\end{array}$ & Human \\
\hline & $1 \cdot 1$ & & & a a $a$ & 9 & $A$ & Mouse \\
\hline \multirow[t]{2}{*}{6} & 1.06 & $663 / 664$ & ...TTGGA & gtaagtaaaa. & ttatttttag & $\underset{\mid}{\text { CCCAC. . }}$ & Human \\
\hline & 0.76 & & $A C$ & & C $\quad C$ & G & Mouse \\
\hline
\end{tabular}

For the characterisation of human PGDH transcriptional control, JEG-3 choriocarcinoma cells were transfected with the PGDH promoter/ luciferase reporter gene constructs depicted in Fig. 3. Vectors encoding AP-1 protein (c-jun and c-fos) were co-transfected to activate AP-1-dependent transcription in the absence or presence of co-expressed Ets-1. The PGDH-388/luc3 construct, which encompasses the $\mathrm{PE}$ region $(-235 /-153)$, was not significantly induced by AP-1 or Ets-1 alone or in combination, nor were the mutants of PGDH-388/luc3 in which the putative AP-1 or Ets binding sites are mutated individually or in combination (Fig. 4). In contrast, the PGDH-DE/-80/luc3 construct, in which the DE region $(-2152 /-1944)$ is fused to the minimal homologous promoter element $-80 /-8$ relative to the start ATG, displayed much higher basal activity. In addition, the DE region conferred strong responsiveness to AP-1. Transfected Ets-1 did not have any effect on PGDH-DE/-80/luc3. However, mutation of the Ets binding site reduced overall activity of the PGDH-DE construct, while the responsiveness to
AP-1 was retained (see fold inductions, Fig. 4). Mutation of the AP-1 or the CREB2 site diminished the response to AP-1, and the lowest activities were seen with simultaneous mutation of the AP-1 and CREB2 motifs. The residual stimulation seen with constructs in which the AP-1 site is mutated was also observed with the minimal promoter construct PGDH-80/luc3 and is probably due to a cryptic AP-1 motif in the plasmid backbone, as reported by other investigators (Kushner et al. 1994). Mutation of the CREB1 site was without effect on basal or AP-1-stimulated promoter activity (Fig. 4).

We then compared different AP-1 proteins for their ability to stimulate the PGDH-DE/-80/luc3 construct (Fig. 5). Expression vectors for Jun proteins (c-jun, JunB or JunD) were combined with expression vectors for Fos proteins (c-fos, FosB, FosB2, Fra-1 or Fra-2). All these combinations induced the reporter gene more strongly than did any of the vectors alone. Highest reporter gene activity was obtained with c-jun/FosB; c-jun/ c-fos yielded an intermediate extent of stimulation comparable with that seen with most of 

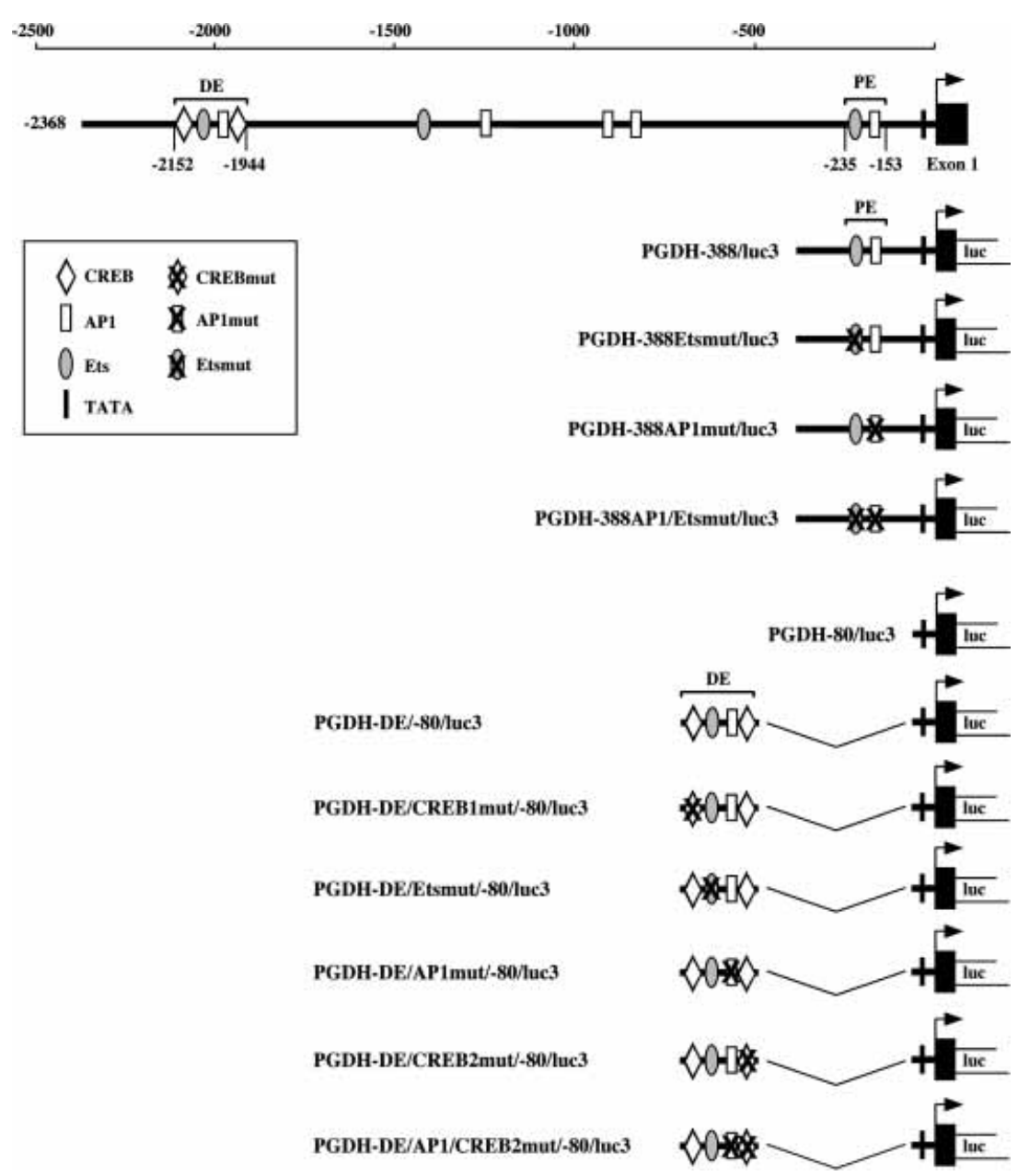

Figure 3 Map of the human PGDH promoter and reporter gene constructs. The 5'-flanking sequence of the human PGDH gene extending to-2368 bp contains a TATA box and putative binding sites for CREB, Ets and AP-1. DE indicates a cluster of distal elements (co-ordinates-2152/-1944) and PE a proximal element (co-ordinates-235/-153). In the promoter/reporter gene construct PGDH-388/luc3, the putative Ets and/or AP-1 binding sites in PE were mutated as indicated. A fragment encompassing DE was inserted in front of a minimal promoter element $(-80 /-8$ relative to the ATG start codon) and the luciferase gene (luc) to yield reporter gene construct PGDH-DE/-80/luc3. Mutations of individual binding sites were introduced as indicated here; sequences are shown in Fig. 7.

the combinations. No significant induction was obtained on the PGDH-388/luc3 construct irrespective of the co-transfected AP-1 family members (data not shown).

To elucidate the role of the GREB1 and CREB2 sites in PGDH-DE, CREB expression vector alone or in combination with c-jun/c-fos was cotransfected with wild-type or mutated PGDH-DE/80/luc3 reporter gene constructs (Fig. 6). CREB alone was able to induce PGDH-DE/-80/luc3, albeit to a lesser extent than was c-jun/c-fos. Co-expression of both families of transcription factors resulted in an additive effect. Mutation of either the AP-1 or the CREB2 site reduced the AP-1 induction to the induction seen with CREB alone. In contrast, mutation of the CREB 1 site blunted the response to CREB while still permitting induction by AP-1. 


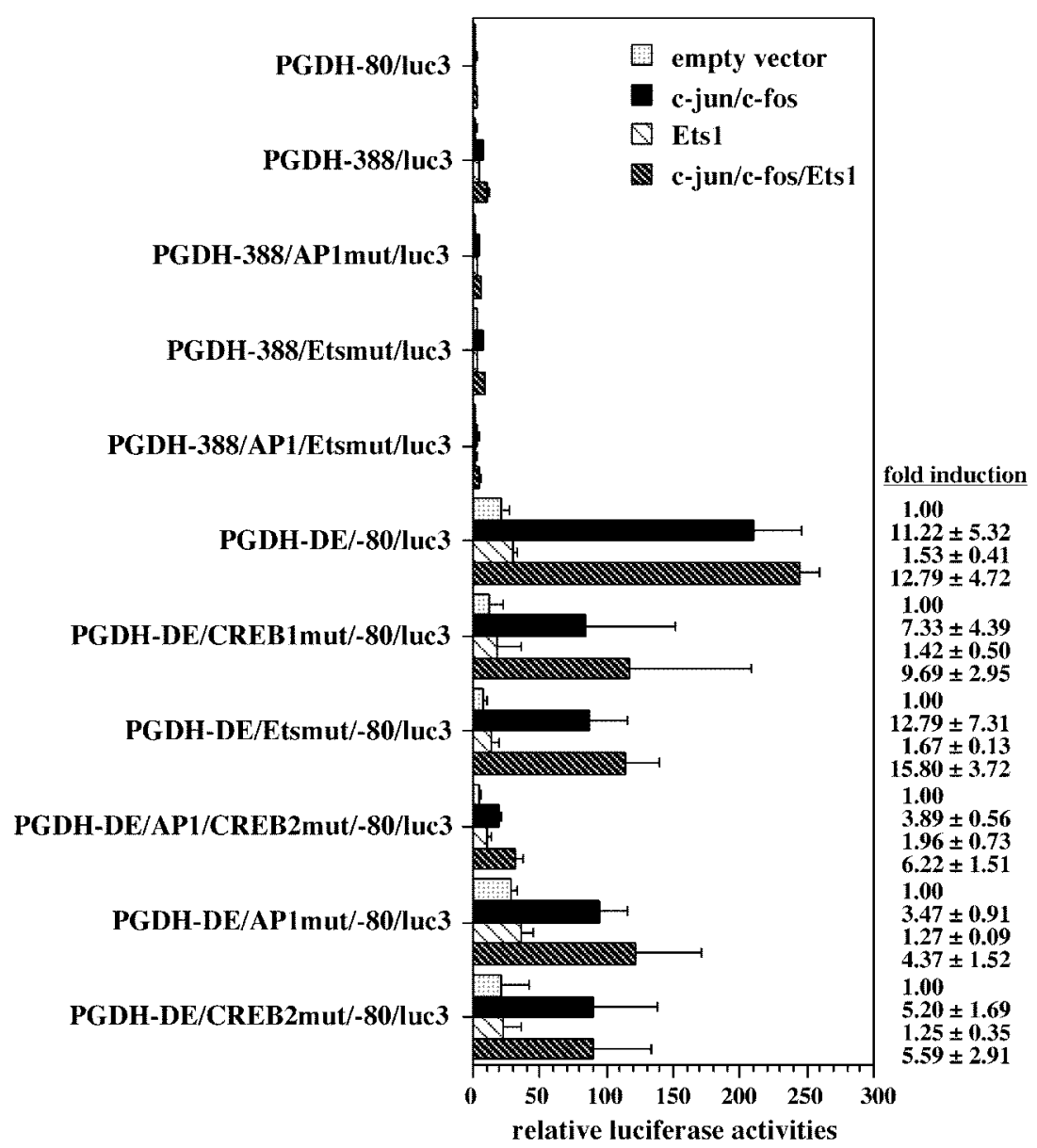

Figure 4 Response of the PGDH promoter to AP-1 and Ets. JEG-3 cells were transiently transfected with the indicated $\mathrm{PGDH}$ promoter/luciferase reporter constructs (see also Fig. 3) and expression vectors for AP-1 protein (c-jun/c-fos), Ets-1, a combination thereof (c-jun/c-fos/Ets1), or the empty expression vectors pcDNA3.1 and pSG5 (empty vector). Relative light units of luciferase activities were normalized by $\beta$-galactosidase activities. The values depicted in the bar graph are the means \pm S.D. from three independent experiments; the activities are expressed relative to those of the minimal promoter construct PGDH-80/luc3 in the presence of the empty vector. Values shown on the right represent fold inductions where activities obtained for each reporter in the presence of empty vector were set to ' 1 ' (means \pm S.D. from three independent experiments).

\section{Characterisation of AP-1, Ets and CREB binding sites in the PGDH promoter by EMSA} In vitro $\mathrm{DNA}$ /protein binding studies (EMSA) were used to confirm functionality of potential binding sites in the PGDH promoter. Nuclear extracts from Jurkat cells, which had been stimulated with phorbol ester and Ionomycin, were used as the source of nuclear protein. Jurkat cells express PGDH mRNA at a level comparable with that seen in placenta (Greenland et al. 2000). Oligonucleotides comprising the proximal Ets and AP-1 sequences (PE/Ets, PE/AP1) and oligonucleotides with point mutations of the critical bases (PE/Etsm, $\mathrm{PE} / \mathrm{AP} 1 \mathrm{~m}$ ) were used as probes and competitors. Likewise, oligonucleotides carrying the potential binding sites from the distal region (DE/CREB1, DE/Ets, DE/AP1, DE/CREB2) and mutated sequences thereof were employed (Fig. 7). 


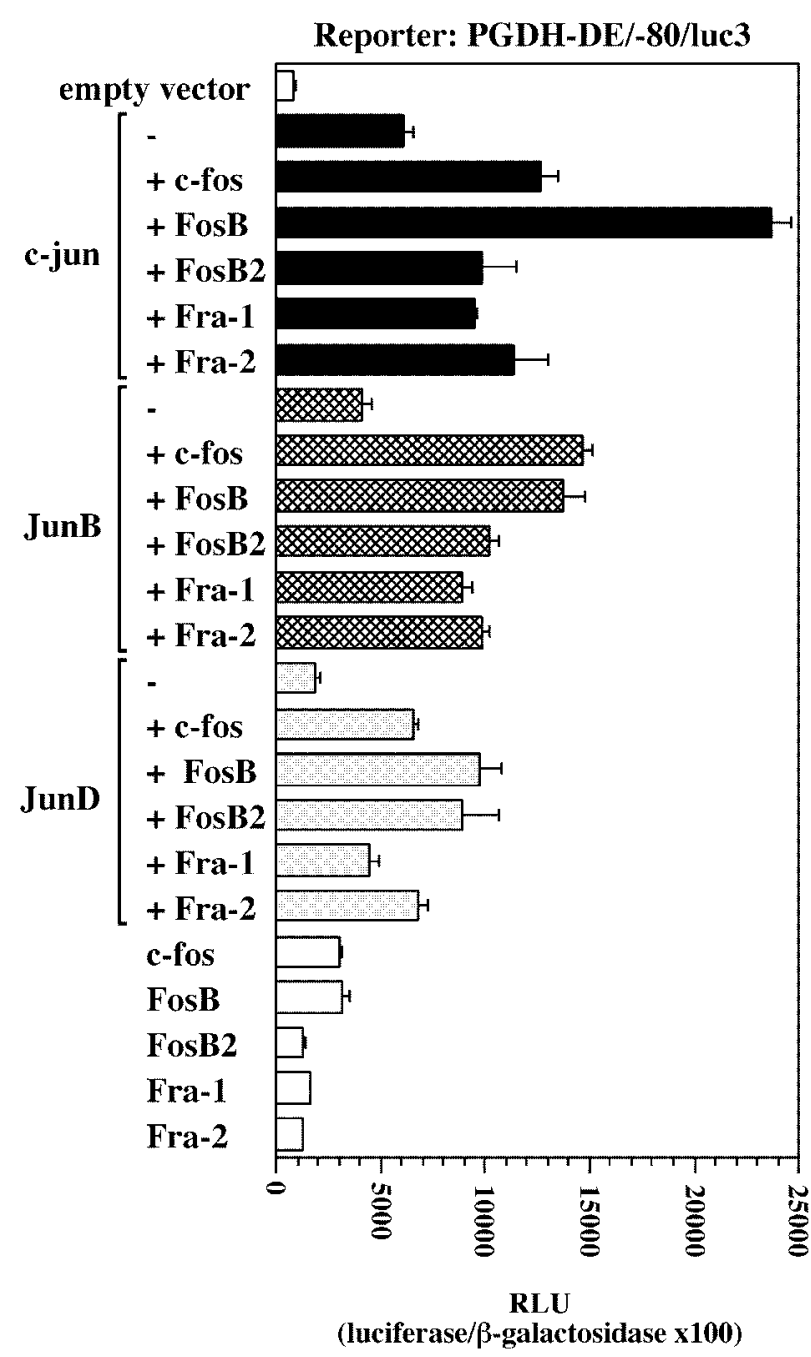

Figure 5 Response of the PGDH promoter to different AP-1 proteins. JEG-3 cells were transiently transfected with PGDH-DE/-80/luc3 and expression vectors for the indicated AP-1 proteins alone or in combination, or the empty expression vector pcDNA3.1 (empty vector,-). Relative light units (RLU) of luciferase activities were divided by RLU of $\beta$-galactosidase activities. The values are the means of triplicate determinations \pm S.D. of a representative experiment.

To ascertain the presence of AP-1 proteins in Jurkat nuclear extracts, an AP-1 consensus response element was used as the probe. A pronounced complex was formed which was readily competed by a 20-fold molar excess of unlabelled AP-1 element (Fig. 8). A much weaker DNA/protein complex was formed on PE/AP1 which could be competed by a 100-fold excess of unlabelled PE/AP1 but not PE/AP1m. A 500-fold excess of consensus AP-1 element was required to reduce binding, indicating that the protein(s) interacting with $\mathrm{PE} / \mathrm{AP} 1$ are distinct from those interacting with AP-1 consensus.

We next applied the same experimental protocol to the distal AP-1 site, DE/AP1. This probe produced a strong complex with Jurkat nuclear extracts, comparable with that obtained with the consensus AP-1 element (Fig. 9A). Binding was competed by 20-fold excesses of unlabelled $\mathrm{DE} / \mathrm{AP} 1$ and consensus AP-1 elements, but not by the mutated DE/AP1 site (DE/APlm) even at a 500-fold molar excess. By supershift analysis, proteins binding to DE/AP1 could be identified as c-fos, JunB, JunD and phosphorylated c-jun, whereas antibodies to other members of the AP-1 family (FosB, Fra-1, Fra-2) did not interact (Fig. 9B).

The proximal and distal Ets binding elements were then analysed. Jurkat cells were shown to contain significant amounts of nuclear proteins binding to an Ets consensus site. A 100- to 500-fold excess of unlabelled Ets consensus was required to compete this binding (Fig. 10A and B, lanes 1-4). $\mathrm{PE} /$ Ets also strongly bound proteins from Jurkat cells, and competition was achieved with 20- to 100-fold excess of unlabelled PE/Ets but not with $\mathrm{PE} /$ Etsm. However, consensus Ets element even at a 500-fold excess did not compete for this binding (Fig. 10A, lanes 9-14). An antibody to Ets-1/Ets-2 did not produce a supershift of the complex formed with PE/Ets (Fig. 10A, lanes 15-16).

The distal Ets site, DE/Ets, also readily formed a complex with Jurkat nuclear proteins which could be competed by 100 - to 500-fold excess of unlabelled DE/Ets but not mutated DE/Etsm. However, in contrast to $\mathrm{PE} / \mathrm{Ets}$, binding to DE/Ets could also be competed by Ets consensus element at a 100-fold excess (Fig. 10B, lanes 5-14). Again, an Ets-1/Ets-2-specific antibody did not supershift the complex formed on DE/Ets (Fig. 10B, lanes 15-16), indicating that an Ets factor other than Ets-1 or Ets-2 binds this motif.

Finally, the potential CREB binding sites in the distal PGDH promoter region were subjected to gelshift analysis. Jurkat nuclear extracts contained significant amounts of CRE binding proteins, as shown in Fig. 11 (A, B and C, lanes 1-4) on a CRE consensus probe. Competition was achieved with 20- to 100-fold excess of unlabelled CRE. The 5' 


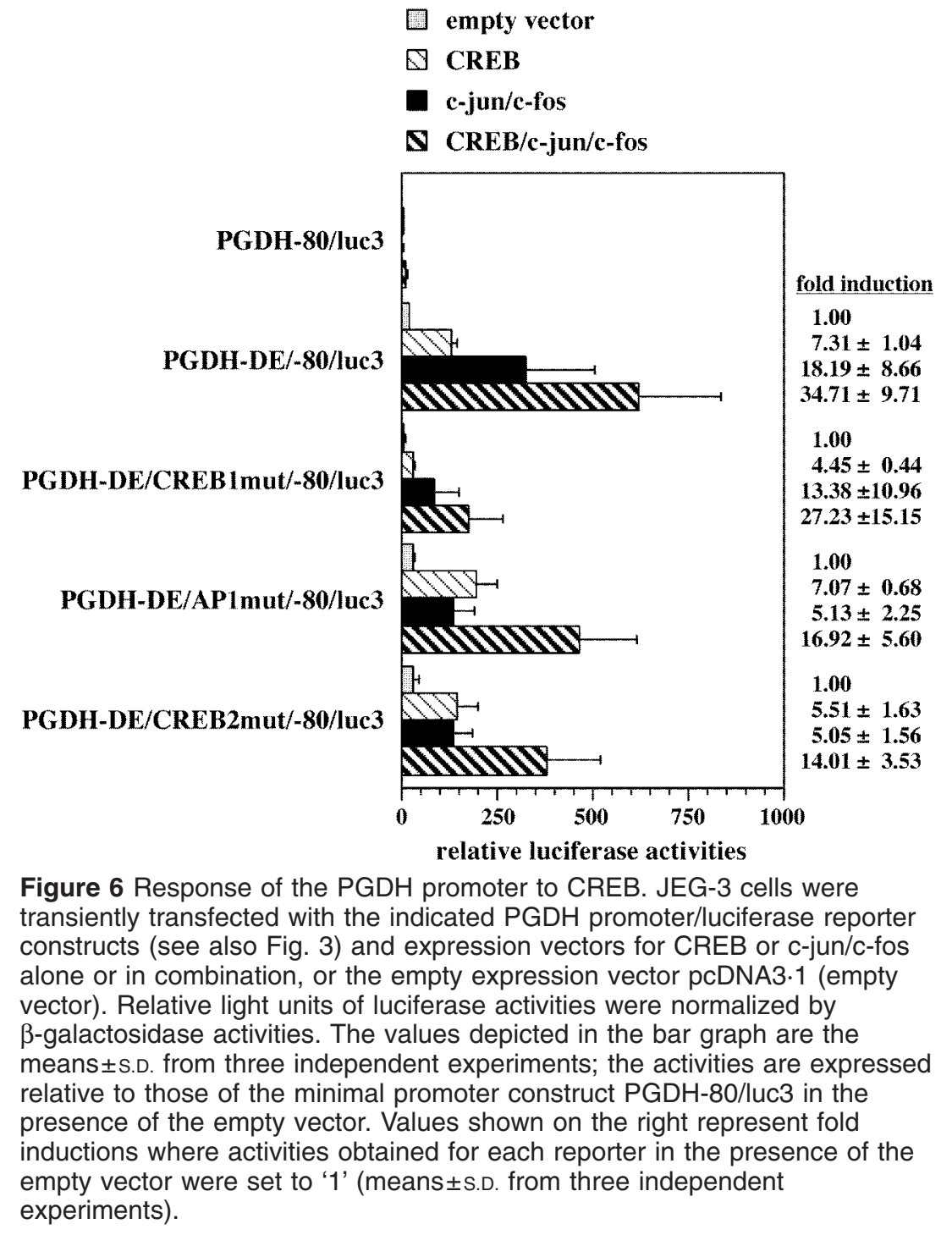

CREB element of the PGDH promoter, DE/ CREB1, also formed a complex with nuclear extracts which was competed both by unlabelled DE/CREB 1 and CRE consensus at a 100-fold excess, but not by the mutated sequence, DE/CREB 1m (Fig. 11A, lanes 5-14). Different binding characteristics were observed with the $3^{\prime}$ CREB element, DE/CREB2. The pronounced complex formed with nuclear proteins from Jurkat cells was readily competed by 20 -fold excess of unlabelled DE/CREB2, but not by DE/CREB2m or by consensus CRE even at 500-fold molar excess (Fig. 11B, lanes 5-14). The latter observation indicated that proteins binding to DE/CREB2 were distinct from CRE binding proteins such as CREB or GRE modulator (CREM). We therefore tested whether DE/CREB2 possibly interacted with proteins from the AP-1 family of transcription factors. To that end, GRE consensus, DE/CREB 1 and DE/CREB2 were prepared as probes and incubated with Jurkat nuclear extracts. For competition, AP-1 consensus element was employed. All three probes formed complexes with the nuclear proteins. These were fully competed by as little as 20-fold excess of AP-1 consensus in the case of CRE and DE/CREB1, but not in the case of DE/CREB2. Binding to this probe could not even be competed by a 500-fold excess of AP-1 sequence 


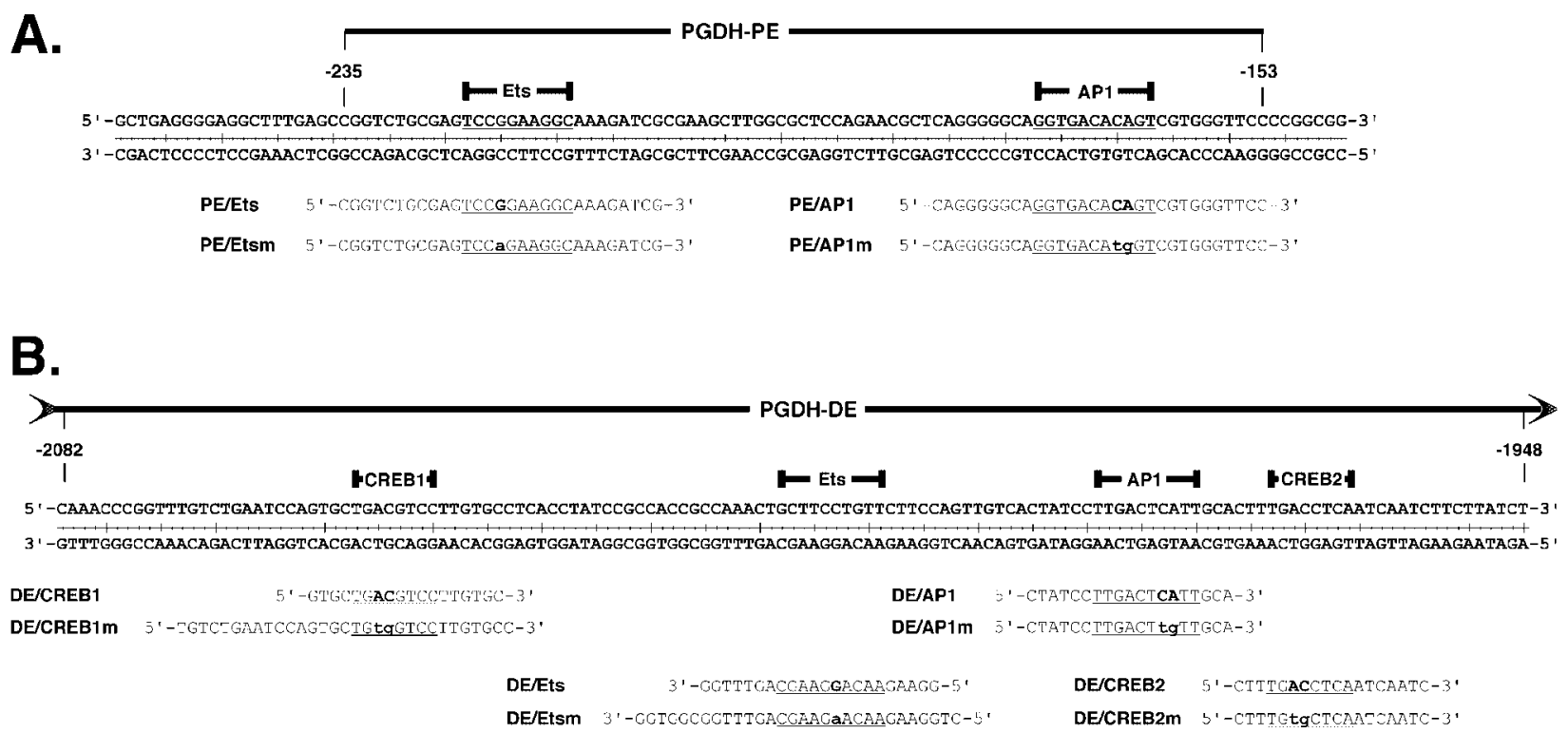

Figure 7 Sequences of potential binding sites and mutations thereof in the PGDH promoter. (A) Ets and AP-1 binding elements in the PGDH-PE region (co-ordinates-235/-153 relative to the start ATG) are underlined and bases predicted to be critical for binding are shown in bold type. The sense sequences of double-stranded oligonucleotides used as probes or competitors in EMSA are shown below the genomic sequence; mutated oligonucleotides carry the suffix ' $m$ ', and mutated bases are in bold lower case letters. (B) A portion of the PGDH-DE region, encompassing two potential CREB binding sites (CREB1, CREB2), an Ets and an AP-1 binding sequence is shown. Note that the Ets binding sequence is on the lower strand, and the corresponding oligonucleotides are printed in the $3^{\prime}-5^{\prime}$ direction.

(Fig. 11C). Taken together, proteins binding to DE/CREB2 cannot be competed by AP-1 or by CRE consensus elements, whereas DE/CREB 1 appears to bind both AP-1 and CREB proteins with similar affinities.

\section{Discussion}

The complete human PGDH gene including $3 \cdot 5 \mathrm{~kb}$ of the 5'-flanking region has been cloned. Alignment of splice junctions with the mouse gene shows a high degree of conservation but the sizes of the human PGDH gene introns are much larger. While the human gene spans $31 \mathrm{~kb}$, the mouse PGDH gene is only $11.3 \mathrm{~kb}$ in size (Matsuo et al. 1997). Within $2 \cdot 4 \mathrm{~kb}$ of the 5 '-flanking region of the human PGDH gene, five putative AP-1, four Ets and two CREB transcription factor binding sites have been identified by computerised search (Greenland et al. 2000). In a previous study, using the full-length promoter construct PGDH-2368/ luc3 transfected into primary cultures of myometrial smooth muscle cells, we observed induction of transcription in response to phorbol ester.

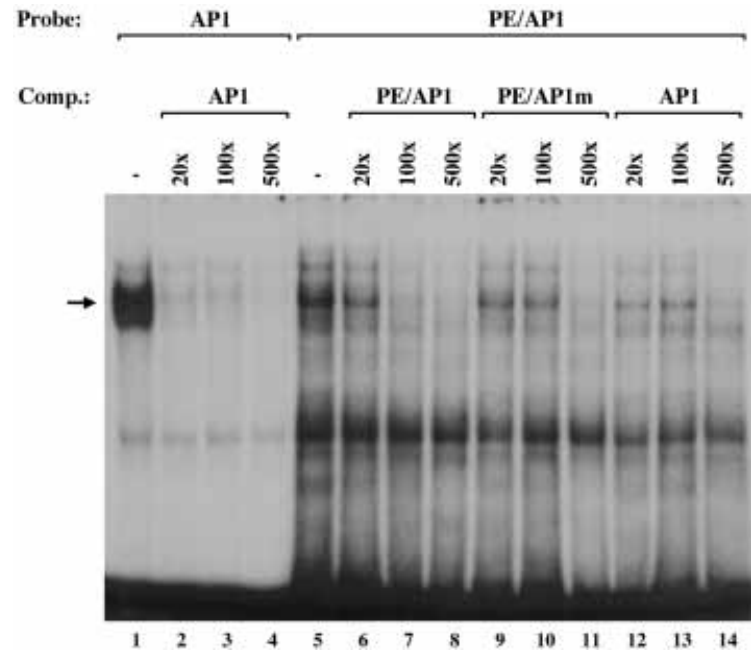

Figure 8 Gelshift analysis of the proximal AP-1 binding sequence. Jurkat cell nuclear extract $(5 \mu \mathrm{g})$ was incubated with ${ }^{32} \mathrm{P}$-labelled double-stranded AP-1 consensus element (lanes 1-4) or the PE/AP1 element from the PGDH-PE region (see Fig. 7A) (lanes 5-14). Competition (Comp.) was carried out with 20-, 100- or 500 -fold molar excess of unlabelled AP-1 consensus element (lanes 2-4, 12-14), PE/AP1 element (lanes $6-8)$ or a mutation thereof (PE/AP1m; lanes 9-11). The specific AP-1 complex is indicated by an arrow. 


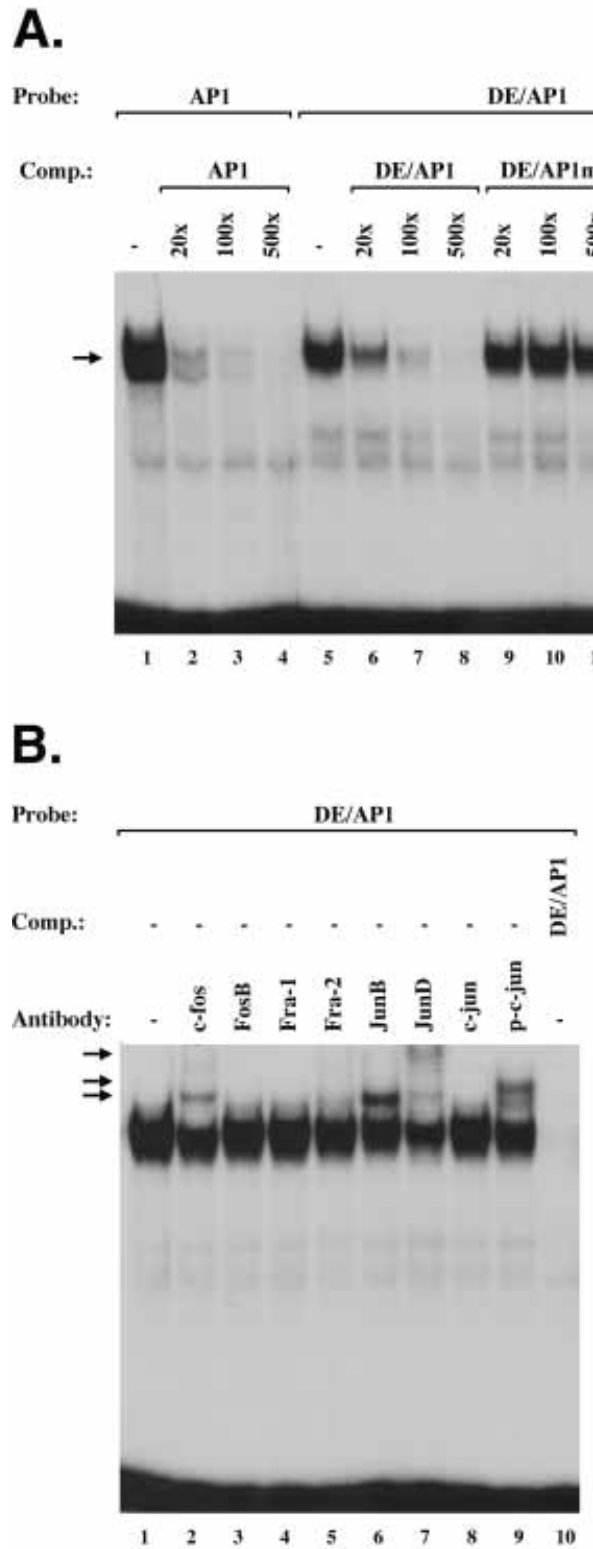

Figure 9 Gelshift analysis of the distal AP-1 binding sequence. (A) Jurkat cell nuclear extract was incubated with ${ }^{32} \mathrm{P}$-labelled double-stranded AP-1 consensus element (lanes 1-4) or the DE/AP1 element from the PGDH-DE region (see Fig. 7B) (lanes 5-14). Competition (Comp.) was carried out with 20-, 100- or 500-fold molar excess of unlabelled AP-1 consensus element (lanes 2-4, 12-14), DE/AP1 element (lanes 6-8) or a mutation thereof (DE/AP1m; lanes 9-11). The specific AP-1 complex is indicated by an arrow. (B) Jurkat cell nuclear extract was incubated with DE/AP1 as the probe and subjected to supershift analysis by addition of the indicated antibodies to AP-1 proteins (lanes 1-9). A 500-fold excess of unlabelled probe was added in lane 10. Supershifted complexes are indicated by arrows.
This induction was abolished by a dominant negative to AP-1, indicating involvement of activated AP-1 (Greenland et al. 2000). In addition, promoter activity in these cells could also be stimulated by Ets-1, Ets-2 and polyomavirus enhancer activator 3 (PEA3), members of the Ets family of transcription factors, and Ets-dependent activation was repressed by co-expression of a dominant negative to AP-1, pointing to a co-operation between Ets and AP-1 proteins. Two regions in which putative Ets and AP-1 sites appear in clusters, PGDH-DE and PGDH-PE, have been analysed more closely in this report.

In transfection experiments we demonstrated that PGDH-DE confers AP-1 inducibility on the minimal homologous promoter in the choriocarcinoma cell line JEG-3, whereas the promoterproximal region failed to convey significant activation by AP-1, in keeping with the observed strong binding of AP-1 proteins to PGDH-DE in EMSA, but the very weak interaction of AP-1 proteins with PGDH-PE. The core sequence of DE/AP1 represents the high affinity AP-1 consensus TGACTCA (Karin et al. 1997, Chinenov \& Kerppola 2001), whereas PE/AP1 is not a perfect palindrome (TGACACA). Supershift analysis revealed the presence of c-fos, JunB, JunD and phosphorylated c-jun in DNA/protein adducts formed with DE/AP1 and Jurkat cell nuclear extracts. In co-transfection experiments, most combinations of Jun and Fos proteins were able to activate PGDH-DE, c-jun/FosB being the most potent heterodimer. Surprisingly, even FosB2 enhanced the transcriptional activation by Jun proteins. In the original report, FosB2, which is a C-terminally truncated splice variant of FosB, has been characterised as a negative regulator of transcription (Yen et al. 1991).

In JEG-3 cells, Ets-1 alone neither transactivated through the distal nor through the proximal element in transient transfections even though the distal element, DE/Ets, apparently binds Ets factors in vitro. Factors present in Jurkat nuclear extracts, which interact with DE/Ets, appear not to be Ets-1 or Ets-2, as evidenced by supershift analysis. The Ets family members specifically binding to DE/Ets remain to be identified. Although the pronounced binding of proteins to PE/Ets could be abolished by a single point mutation in the predicted Ets binding core motif, binding was not effectively competed by addition of 


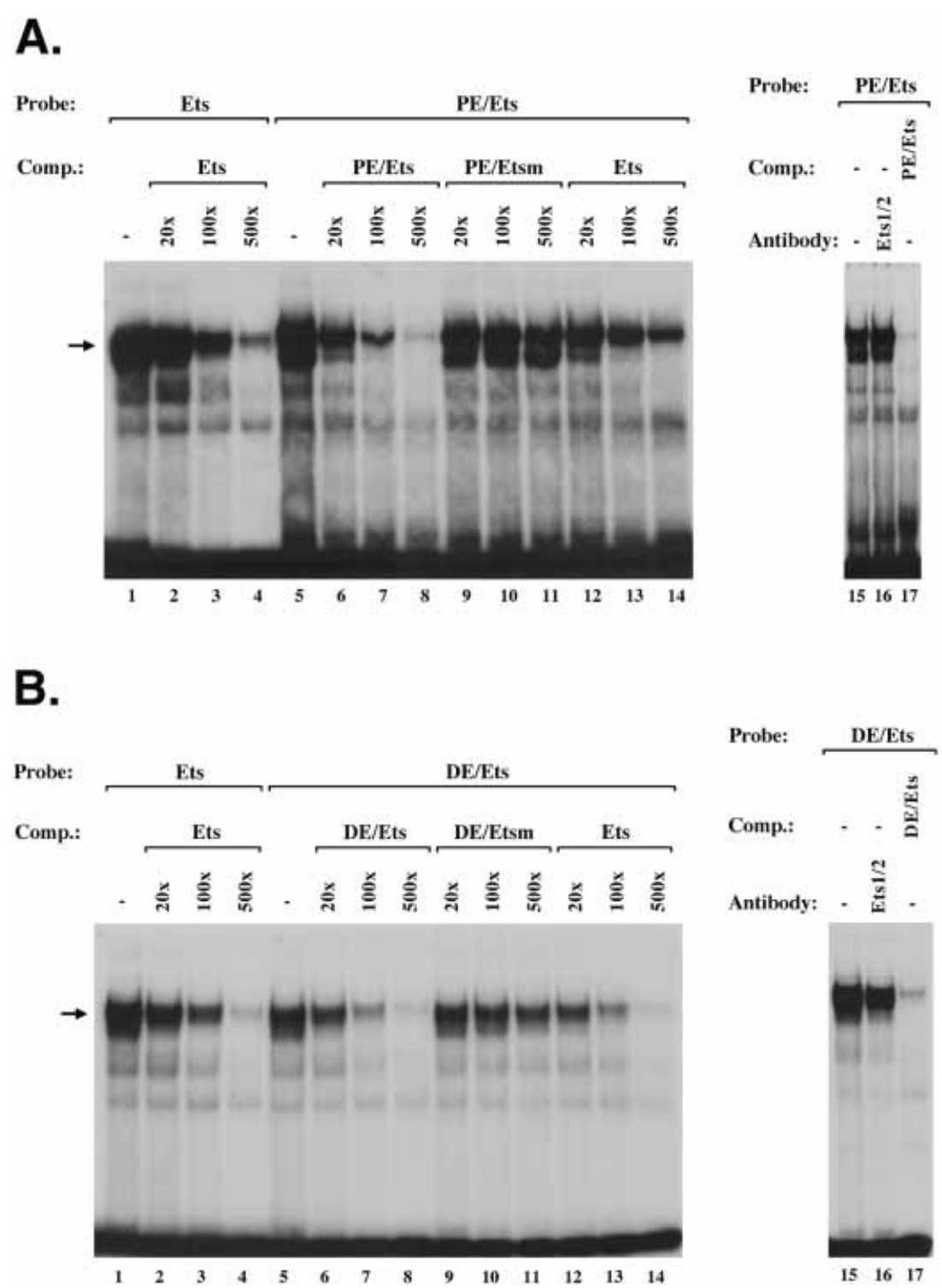

Figure 10 Gelshift analysis of the proximal and distal Ets binding sequences. (A) Jurkat cell nuclear extract was incubated with ${ }^{32} \mathrm{P}$-labelled doublestranded Ets consensus element (lanes 1-4) or the PE/Ets element from the PGDH-PE region (see Fig. 7A) (lanes 5-17). Competition (Comp.) was carried out with $20-, 100-$ or 500 -fold molar excess of unlabelled Ets consensus element (lanes 2-4, 12-14), PE/Ets element (lanes 6-8, 17) or a mutation thereof (PE/Etsm; lanes 9-11). For supershift analysis, an antibody to Ets-1/Ets-2 was added (lane 16). The specific Ets complex is indicated by an arrow. (B) The same protocol as in (A) was employed but using the distal Ets element $\mathrm{DE} / \mathrm{Ets}$ as the probe and $\mathrm{DE} / \mathrm{Ets}$ and $\mathrm{DE} / \mathrm{Etsm}$ as competitors (see Fig. 7B).

an excess of consensus Ets binding sequence. We conclude that the factors interacting with $\mathrm{PE} / \mathrm{Ets}$ are distinct from those interacting with DE/Ets, where binding could be readily competed with consensus Ets binding site. Even though transfection of the Ets-1 expression vector did not induce reporter gene activity through the distal element in the construct PGDH-DE/-80/luc3, point mutation 

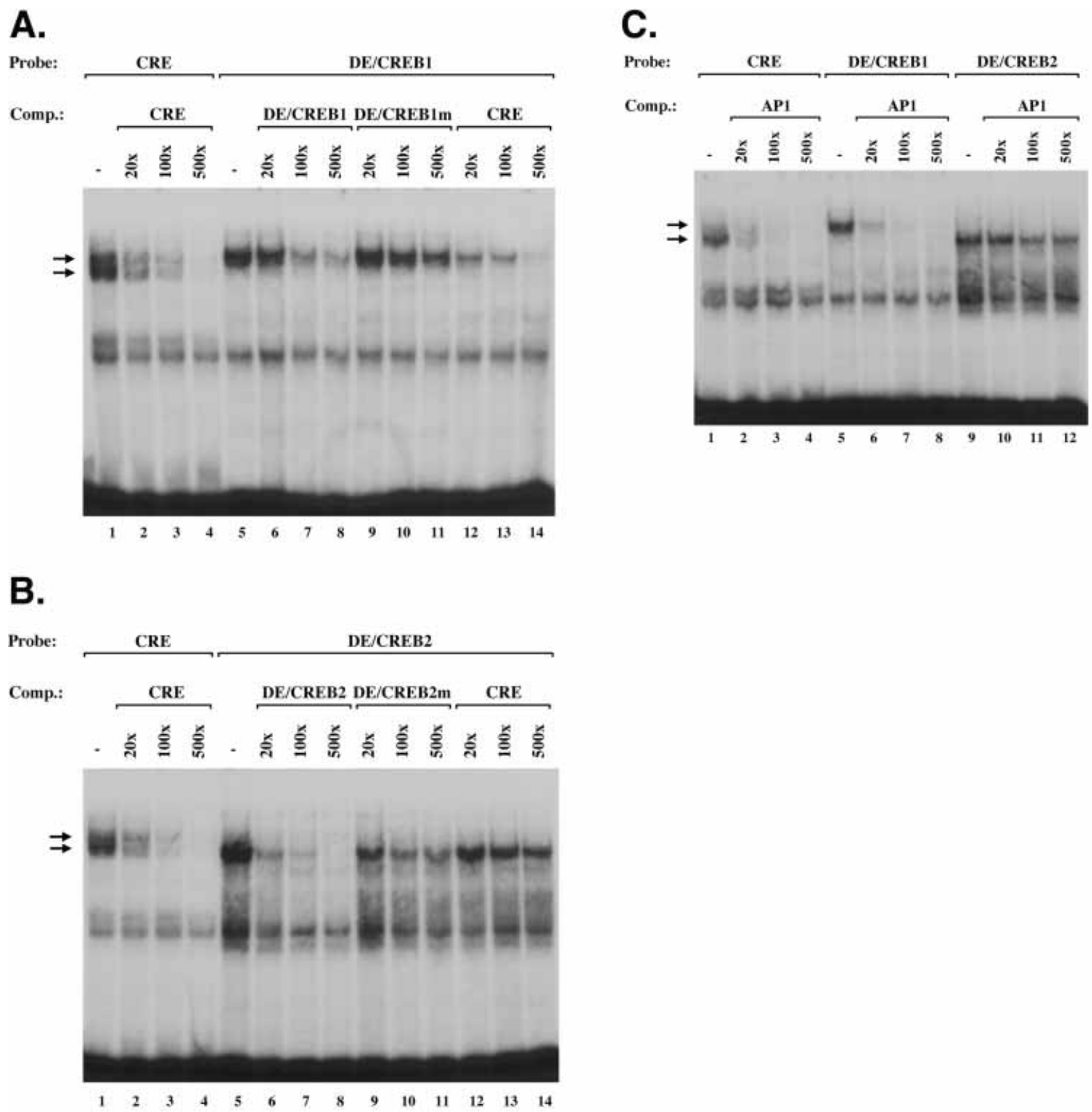

Figure 11 Gelshift analysis of the distal CREB1 and CREB2 binding sequences. (A) Jurkat cell nuclear extract was incubated with ${ }^{32} \mathrm{P}$-labelled double-stranded CRE (a consensus CREB binding sequence) (lanes 1-4) or the DE/CREB1 element from the PGDH-DE region as the probe (see Fig. 7B) (lanes 5-14). Competition (Comp.) was carried out with 20-, 100- or 500-fold molar excess of unlabelled CRE consensus element (lanes 2-4, 12-14), DE/CREB1 element (lanes 6-8) or a mutation thereof (DE/ CREB1m; lanes 9-11). The specific CRE-binding complexes are indicated by arrows. (B) The same protocol as in (A) was employed but using the second CREB element, DE/CREB2, as the probe and DE/ CREB2 and DE/CREB2m as competitors (see Fig. 7B). (C) Consensus CRE (lanes 1-4), DE/CREB1 (lanes 5-8) or DE/CREB2 (lanes 9-12) were used as probes. Binding was competed with 20-, 100- or 500 -fold molar excess of AP-1 consensus binding site (lanes $2-4,6-8,10-12$ ). Specific complexes are indicated by arrows. 
of the predicted Ets site reduced promoter activity. It is conceivable that endogenous Ets factors, present in JEG-3 cells, interact with PGDH-DE and contribute to basal transcription.

We showed previously that activation of the full-length promoter construct PGDH-2368/luc3 by the Ets factor PEA3 is repressed by a dominant negative to GREB (Greenland et al. 2000). In the present study, we can now demonstrate binding of CREB or related factors to the DE/CREB 1 site in vitro. The functional significance of this site was further confirmed by the observation that mutation of CREB1 diminished the CREB-mediated induction of the PGDH-DE/-80/luc3 reporter construct. The CREB2 site rather appears to be involved in mediating AP-1 inducibility. The nuclear proteins binding to this site neither interact with a consensus CRE nor an AP-1 site and remain to be identified.

In summary, we have characterised the distal element of the PGDH promoter as an integrator of activating signals by AP-1, Ets and CREB transcription factors.

\section{Acknowledgements}

We wish to thank Gabriele Rieck for excellent technical assistance, Prof. Dr F Leidenberger for his continuous support, and Drs R Goodman, G E DiMattia, PR Dobner, $M$ Robinson and $\mathrm{B}$ Wasylyk for plasmid vectors.

\section{References}

Bracken KE, Elger W, Jantke I, Nanninga A \& Gellersen B 1997 Cloning of guinea pig cyclooxygenase-2 and 15-hydroxyprostaglandin dehydrogenase cDNAs: steroid-modulated gene expression correlates to PGF2 $\alpha$ secretion in cultured endometrial cells. Endocrinology 138 237-247.

Chinenov Y \& Kerppola TK 2001 Close encounters of many kinds: Fos-Jun interactions that mediate transcription regulatory specificity. Oncogene 20 2438-2452.

Coggins KG, Nguyen MS, Audoly L, Coffman TM \& Koller BH 2002 Metabolism of PGE2 $\alpha$ by prostaglandin dehydrogenase is essential for remodeling the ductus arteriosus. Nature Medicine $\mathbf{8}$ 91-92.

Ensor CM \& Tai HH 1995 15-Hydroxyprostaglandin dehydrogenase. Fournal of Lipid Mediators and Cell Signalling 12 313-319.

Ensor CM, Yang JY, Okita RT \& Tai HH 1990 Cloning and sequence analysis of the cDNA for human placental $\mathrm{NAD}^{+}$. dependent 15-hydroxyprostaglandin dehydrogenase. Fournal of Biological Chemistry 265 14888-14891.

Giannoulias D, Patel FA, Holloway FA, Lye SJ, Tai HH \& Challis JRG 2002 Differential changes in 15-hydroxyprostaglandin dehydrogenase and prostaglandin $\mathrm{H}$ synthase (types I and II) in human pregnant myometrium. Fournal of Clinical Endocrinology and Metabolism 87 1345-1352.
Greenland KJ, Jantke I, Jenatschke S, Bracken KE, Vinson C \& Gellersen B 2000 The human $\mathrm{NAD}^{+}$-dependent 15-hydroxyprostaglandin dehydrogenase gene promoter is controlled by Ets and activating protein- 1 transcription factors and progesterone. Endocrinology 141 581-597.

Harrison RJ, McNeil GP \& Dobner PR 1995 Synergistic activation of neurotensin/neuromedin $\mathrm{N}$ gene expression by c-Jun and glucocorticoids: novel effects of Fos family proteins. Molecular Endocrinology 9 981-993.

Karin M, Liu Z \& Zandi E 1997 AP-1 function and regulation. Current Opinion in Cell Biology 9 240-246.

Kushner PJ, Baxter JD, Duncan KG, Lopez GN, Schaufele F, Uht RM, Webb P \& West BL 1994 Eukaryotic regulatory elements lurking in plasmid DNA: the activator protein-1 site in pUC. Molecular Endocrinology 8 405-407.

Li R, Pei H \& Watson DK 2000 Regulation of Ets function by protein-protein interactions. Oncogene $196514-6523$.

López Bernal A \& Watson SP 1992 Cellular endocrinology. In Prostaglandins and the Uterus, pp 213-235. Eds JO Drife \& AA Colder. New York: Springer.

Matsuo M, Ensor CM \& Tai HH 1996 Cloning and expression of the cDNA for mouse $\mathrm{NAD}^{+}$-dependent 15-hydroxyprostaglandin dehydrogenase. Biochimica et Biophysica Acta 1309 21-24.

Matsuo M, Ensor CM \& Tai HH 1997 Characterization of the genomic structure and promoter of the mouse $\mathrm{NAD}^{+}$-dependent 15-hydroxyprostaglandin dehydrogenase gene. Biochemical and Biophysical Research Communications 235 582-586.

Mitchell BF, Pogers K \& Wong S 1993 The dynamics of prostaglandin metabolism in human fetal membranes and decidua around the time of parturition. Fournal of Clinical Endocrinology and Metabolism 77 759-764.

Okazaki T, Casey ML, Okita JR, MacDonald PC \& Johnston JM 1981 Initiation of human parturition. XII. Biosynthesis and metabolism of prostaglandins in human fetal membranes and uterine decidua. American Fournal of Obstetrics and Gynecology 139 373-381.

Okita RT \& Okita JR 1996 Prostaglandin-metabolizing enzymes during pregnancy: characterization of $\mathrm{NAD}^{+}$-dependent prostaglandin dehydrogenase, carbonyl reductase, and cytochrome P450-dependent prostaglandin $\Omega$-hydroxylase. Critical Reviews in Biochemistry and Molecular Biology 31 101-126.

Patel FA \& Challis JR 2001 Prostaglandins and uterine activity. Frontiers in Hormone Research 27 31-56.

Pichaud F, Delage-Mourroux R, Pidoux E, Jullienne A \& Rousseau-Merck MF 1997 Chromosomal localization of the type-I 15-PGDH gene to 4q34-q35. Human Genetics 99 279-281.

Pomini F, Patel FA, Mancuso S \& Challis JRG 2000 Activity and expression of 15-hydroxyprostaglandin dehydrogenase in cultured chorionic trophoblast and villous trophoblast cells and in chorionic explants at term with and without spontaneous labor. American Fournal of Obstetrics and Gynecology 182 221-226.

Sangha RK, Walton JC, Ensor CM, Tai HH \& Challis JRG 1994 Immunohistochemical localization, messenger ribonucleic acid abundance, and activity of 15-hydroxyprostaglandin dehydrogenase in placenta and fetal membranes during term and preterm labor. Fournal of Clinical Endocrinology and Metabolism $\mathbf{7 8}$ 982-989.

Schreiber E, Matthias P, Müller MM \& Schaffner W 1989 Rapid detection of octamer binding proteins with 'mini-extracts', prepared from a small number of cells. Nucleic Acids Research 17 6419.

Van Meir CA, Matthews SG, Keirse MJNC, Ramirez MM, Bocking A \& Challis JRG 1997 a 15-Hydroxyprostaglandin dehydrogenase: implications in preterm labor with and without ascending infection. Foumal of Clinical Endocrinology and Metabolism 82 969-976. 
Van Meir CA, Ramirez MM, Matthews SG, Calder AA, Keirse MJNG \& Challis JRG $1997 b$ Chorionic prostaglandin catabolism is decreased in the lower uterine segment with term labour. Placenta 18 109-114.

Yen J, Wisdom RM, Tratner I \& Verma IM 1991 An alternative spliced form of FosB is a negative regulator of transcriptional activation and transformation by Fos proteins. PNAS 88 5077-5081.
Zhang HX, Matsuo M, Zhou HP, Ensor CM \& Tai HH Cloning and expression of the cDNA for rat $\mathrm{NAD}^{+}$-dependent 15-hydroxyprostaglandin dehydrogenase. Gene 188 41-44.

Received in final form 3 April 2003

Accepted 22 April 2003 